\title{
Estimation of Nitrogen Content and Marketable Yield Using Chlorophyll Readings
}

\author{
Xiaoyan Pan, Hongxia Cao ", Jiankai Zhang, Zijian He, Bingjie Du \\ Key Laboratory of Agricultural Soil and Water Engineering in Arid and Semiarid Areas, Ministry of Education, Northwest Agriculture \& \\ Forestry University, Yangling, China
}

Email address:

pxy520@nwafu.edu.cn (Xiaoyan Pan),nschx225@nwafu.edu.cn (Hongxia Cao)

${ }^{*}$ Corresponding author

To cite this article:

Xiaoyan Pan, Hongxia Cao, Jiankai Zhang, Zijian He, Bingjie Du. Estimation of Nitrogen Content and Marketable Yield Using Chlorophyll Readings. International Journal of Applied Agricultural Sciences. Vol. 7, No. 5, 2021, pp. 219-231. doi: 10.11648/j.ijaas.20210705.12

Received: September 10, 2021; Accepted: September 26, 2021; Published: October 12, 2021

\begin{abstract}
Accurate estimation of nitrogen content and yield is crucial and these can be predicted through chlorophyll readings as indicators. To explore the diagnosis model, a field experiment was conducted in a greenhouse at Yang ling, northwest China. The SPAD values results estimated the nitrogen status, total marketable yield, and rates of reduction in market yield. There was a positive correlation between SPAD value at the middle leaf (MD-SPAD) and nitrogen accumulation, and between SPAD value under the leaf (UD-SPAD) and nitrogen accumulation $\left(\mathrm{R}^{2}=0.37-0.78, \mathrm{P}<0.01, \mathrm{n}=27\right)$. The MD-SPAD and UD-SPAD were positively correlated with total marketable yield during the growth period $\left(\mathrm{R}^{2}=0.43-0.59, \mathrm{P}<0.01, \mathrm{n}=27\right)$. However, a poor correlation was observed at the upper leaf (UP-SPAD) in the expanding fruit period but was better in the mature period. Moreover, the nitrogen nutrition index (NNI) and MD-SPAD were positively correlated $\left(\mathrm{R}^{2}=0.42-0.55, \mathrm{P}<0.01, \mathrm{n}=54\right)$. There $\mathrm{SPAD}$ values and reduction rates of ranks were positively correlated in marketable yield $\left(\mathrm{R}^{2}=0.48-0.52, \mathrm{P}<0.01, \mathrm{n}=54\right)$, including middle fruit yield (MFY) and big fruit yield (BFY). This was similar between SPAD values and reduction rates of total marketable yield $\left(\mathrm{R}^{2}=50, \mathrm{P}<0.01, \mathrm{n}=54\right)$. This indicated that nitrogen accumulation estimates including nitrogen accumulation in stem, leaf, fruit, and the overall nitrogen accumulation, as well as total marketable yield, is not accurate via UP-SPAD during fruit expanding period but it is opposite in mature period. When simultaneously considering estimation of nitrogen accumulation, NNI and marketable yield using chlorophyll readings, which were adopted by mean of SPAD values the different leaf positions or SPAD values at the middle leaf. On the other hand, UP-SPAD should be cautiously used to estimate nitrogen status, yield, and yield reduction rates. The overall marketable yield was optimal under W2 of $2488 \mathrm{~m}^{3} \mathrm{hm}^{-2}$ and N2 of $300 \mathrm{kghm}^{-2}$. The reduction rates during middle fruit yield, big fruit yield, and total marketable yield ranged from $31 \%-38 \%$. The big fruit yield was the highest, indicating that the big fruit yield is highly affected by severe water stress in the blossom and fruit period.
\end{abstract}

Keywords: Nitrogen Status, SPAD Value, Relationship, Leaf Position, Marketable Yield

\section{Introduction}

Recently, expansion of vegetable planting in greenhouse, uncontrolled irrigation and use of nitrogen fertilizers have led to waste of water resources and environmental pollution [1, 2]. Appropriate irrigation and application of the right amount of nitrogen fertilizer could improve yield, nitrogen uptake and efficiency of water use in crops such as tomato [3, 4], wheat [5, 6], and cucumber [7, 8]. Therefore, type of irrigation and amount of nitrogen fertilizer used could greatly increase production and nitrogen uptake in crops. Chlorophyll meter reading, to some extent can assess the level of nitrogen and the resultant yield in crops such as rice [9] and potato [10]. Chlorophyll content can be rapidly measured using chlorophyll meter, a simple and universal diagnostic instrument. Studies have revealed a good relationship between chlorophyll, nitrogen uptake and yield $[11,12]$. Nitrogen nutrition index in crops has been estimated by chlorophyll readings [13-15]. However, for an accurate model on the basis of estimation of nitrogen content and yield by chlorophyll readings, relationships of chlorophyll content in different growth periods with nitrogen status and yield may exhibit a dynamic change. A previous study showed a linear relationship between 
chlorophyll and concentration of leaf nitrogen [16], but study also showed a index relationship between chlorophyll content and nitrogen accumulation [17]. The difference in the relationships may be due to non-uniform selection standard of leaf positions during chlorophyll measurement. Previous studies focused on selection of fully expanded leaf $[12,18-20]$, whereas it does not have uniform position or detailed description. It has been shown that Chlorophyll sensitivity of frond is based on age. Generally, the classification accuracy tends to decrease as frond gets older [21], which may depict dynamic change of chlorophyll content in young or old leaf. The upper one-third of the plant proved to be a reliable tissue source in five specialty cut flowers, generally, young leaf samples collected early in the season had higher nutrient concentrations as compared with the same leaf position at mid or late season [22], which indicates that physiological metabolism and nutrient status could be affected by different leaf position or growth period. Selection of leaf position and growth period could be particularly important when dealing with evaluated accuracy of nitrogen level with chlorophyll readings. Chlorophyll changes in different growth period, thus the accuracy of the relationship between chlorophyll and nitrogen level or yield may also change. It has also been shown that the relationship of chlorophyll, in the expansion period or mature period, with nitrogen nutrient index and yield are stronger than in seedling stage [23]. Thus, the chlorophyll in different stages of growth could have a significant impact on the assessment of nitrogen level and yield. Thus, the relationship of chlorophyll with level of nitrogen and with yield could be more accurate if chlorophyll measurement is divided in different growth stages or leaf positions.

The objectives of this study were: (1) to investigate the effects of level of irrigation and amount of nitrogen fertilizer applied on chlorophyll readings, nitrogen content and marketable yield (2) to estimate nitrogen content, marketable yield and reduction rate in marketable yield with chlorophyll readings at different positions in stages of growth. (3) To quantify reduction rates of ranks in marketable yield due to water stress during critical growth period.

\section{Materials and Methods}

\subsection{Experimental Site and Materials}

This study was conducted in a greenhouse at an
Agricultural Research Farm of the Agricultural Cooperative in Yang Ling, Shaanxi province, China (latitude $34^{\circ} 17^{\prime} \mathrm{N}$, longitude $108^{\circ} 10^{\prime} \mathrm{E}$, altitude $527 \mathrm{~m}$ ). The study area has a typical semi-arid climate with an average annual rainfall of $632 \mathrm{~mm}$, sunshine of $2163.8 \mathrm{~h}$ and evaporation of $1500 \mathrm{~mm}$. The greenhouse of $40 \mathrm{~m}$ long and $8 \mathrm{~m}$ wide with total planting area $38 \times 7=266 \mathrm{~m}^{2}$ had an east-west orientation, with crop rows aligned north-south. Tomato plants (Kai de dong guan) were transplanted on 02-02-2019 and uprooted on 03-07-2019 during the winter-spring season. Tomato seedlings were evenly transplanted along each edge of the raised bed which was $7 \mathrm{~m}$ long and $0.9 \mathrm{~m}$ wide. The planting spacing and row spacing were $0.35 \mathrm{~m}$ and $0.50 \mathrm{~m}$, respectively. Surface drip irrigation was applied via plastic film mulching. Each dripper had a flow rate of $2.1 \mathrm{~L} \cdot \mathrm{h}^{-1}$ and spacing were $0.35 \mathrm{~m}$ apart. Heavy loam soil with the bulk density of $1.40 \mathrm{~g} \cdot \mathrm{cm}^{3}$ and field water capacity of $0.24 \mathrm{~cm}^{3} / \mathrm{cm}^{3}$ in the $0-60 \mathrm{~cm}$ was used. The available nitrogen, phosphate and total potassium fertilizer content in $0-40 \mathrm{~cm}$ soil layer before planting were $29.69 \mathrm{mg} \cdot \mathrm{kg}^{-1}, \quad 21.51 \mathrm{mg} \cdot \mathrm{kg}^{-1}$, and $174.35 \mathrm{mg} \cdot \mathrm{kg}^{-1}$, respectively.

\subsection{Experiment Design}

Three levels of nitrogen and three levels of irrigation were applied. The three nitrogen fertilizer $(\mathrm{N})$ levels were set as: lower nitrogen (N1) of $150 \mathrm{~kg} / \mathrm{hm}^{2}$, moderate nitrogen (N2) of $300 \mathrm{~kg} / \mathrm{hm}^{2}$ and high nitrogen (N3) of $450 \mathrm{~kg} \mathrm{~N} \mathrm{hm}^{-2}$ as conventional nitrogen fertilizer application, N1 and N2 were a reduction of $66 \% \mathrm{~N} 3$ and $33 \% \mathrm{~N} 3$, respectively. The three levels of irrigation were set as: severe water stress (W1) of $50 \% \mathrm{~W} 3$ in blossom and fruit period, mild water stress (W2) of $75 \% \mathrm{~W} 3$ in blossom and fruit period, full irrigation (W3) of $75 \%-90 \%$ in field water capacity $(75 \%$ as the lower limit and $90 \%$ as the upper limit of field water capacity, respectively) in whole growth period. When the average of soil moisture content in $0-60 \mathrm{~cm}$ soil layers was $75 \%$ water field capacity, irrigation of the plants was started. The frequency of irrigation and time were the same as those of control treatment. A completely random design was used in this study, with 9 treatments, namely: W1N1、W1N2、 W1N3、W2N1、W2N2、W2N3、W3N1、W3N2、W3N3, and each was conducted in triplicate. The details are provided in Table 1 and Table 2.

Table 1. Details of 9 treatments: nitrogen fertilizer application rates and irrigation level rates.

\begin{tabular}{|c|c|c|c|c|}
\hline \multirow{2}{*}{ Treatments } & \multirow{2}{*}{$\mathrm{N}$ rates $\left(\mathbf{k g} \cdot \mathbf{h m}^{-2}\right)$} & \multicolumn{3}{|c|}{ Rates of irrigation levels } \\
\hline & & Seedling period & Blossom and fruit period & Mature period \\
\hline W1N1 & 150 & W3 & $50 \% \mathrm{~W} 3$ & W3 \\
\hline W1N2 & 300 & W3 & $50 \% \mathrm{~W} 3$ & W3 \\
\hline W1N3 & 450 & W3 & $50 \% \mathrm{~W} 3$ & W3 \\
\hline W2N1 & 150 & W3 & $75 \% \mathrm{~W} 3$ & W3 \\
\hline W2N2 & 300 & W3 & $75 \% \mathrm{~W} 3$ & W3 \\
\hline W2N3 & 450 & W3 & $75 \% \mathrm{~W} 3$ & W3 \\
\hline W3N1 & 150 & W3 & W3 & W3 \\
\hline W3N2 & 300 & W3 & W3 & W3 \\
\hline W3N3 & 450 & W3 & W3 & W3 \\
\hline
\end{tabular}


According to the local traditional fertilizer supply, amount of phosphorus fertilizer $(\mathrm{P})$ and potassium fertilizer $(\mathrm{K})$ were $200 \mathrm{~kg} \cdot \mathrm{hm}^{-2}$ and $360 \mathrm{~kg} \cdot \mathrm{hm}^{-2}$, respectively. $100 \% \mathrm{P}, 40 \% \mathrm{~K}$ and nitrogen fertilizer of $100 \mathrm{~kg} \cdot \mathrm{hm}^{-2}$ were applied into the tillage as the base fertilizer. The rest of $\mathrm{K}$ and $\mathrm{N}$ were evenly applied with irrigation water in blossom and fruit period. Nitrogen, phosphorus and potash fertilizer were urea $(\geq 46 \%)$, Superphosphate $\left(\mathrm{P}_{2} \mathrm{O}_{5}: \mathrm{p} \geq 16 \%\right)$, and potassium sulfate $\left(\mathrm{K}_{2} \mathrm{O}\right.$ : $\mathrm{k} \geq 52 \%$ ), respectively. The level of irrigation of each treatment was controlled by water meter. The level of irrigation was 22 $\mathrm{mm}$ on transplanting date and no irrigation was needed for a long time after transplanting to provide a conducive environment for root development. The experimental treatments were carried out after the survival of tomato seedlings and mulch films were placed in the north-south direction before transplanting.

Table 2. Details of the study: level of irrigation and nitrogen fertilizer application.

\begin{tabular}{|c|c|c|c|c|c|c|c|}
\hline \multirow{2}{*}{ Irrigation date } & \multirow{2}{*}{ Growth periods } & \multicolumn{3}{|c|}{ Level of irrigation $(\mathrm{m} 3 \cdot \mathrm{hm}-2)$} & \multicolumn{3}{|c|}{ Nitrogen fertilizer application $(\mathrm{kg} \cdot \mathrm{hm}-2)$} \\
\hline & & W1 & W2 & W3 & N1 & $\mathbf{N 2}$ & N3 \\
\hline 2019.01 .26 & \multirow{3}{*}{ Seedling period } & 1 & 1 & 1 & 100 & 100 & 100 \\
\hline 2019.02 .02 & & 221.19 & 221.19 & 221.19 & 0 & 0 & 0 \\
\hline 2019.02 .22 & & 221.19 & 221.19 & 221.19 & 0 & 0 & 0 \\
\hline 2019.03 .05 & \multirow{3}{*}{ Blossom period } & 110.6 & 165.89 & 221.19 & 0 & 0 & 0 \\
\hline 2019.03 .19 & & 110.6 & 165.89 & 221.19 & 12.5 & 50 & 87.5 \\
\hline 2019.03 .29 & & 110.6 & 165.89 & 221.19 & 0 & 0 & 0 \\
\hline 2019.04 .17 & \multirow{3}{*}{ Fruit expanding period } & 110.6 & 165.89 & 221.19 & 0 & 0 & 0 \\
\hline 2019.04 .29 & & 110.6 & 165.89 & 221.19 & 12.5 & 50 & 87.5 \\
\hline 2019.05 .10 & & 110.6 & 165.89 & 221.19 & 12.5 & 50 & 87.5 \\
\hline 2019.05 .23 & \multirow{5}{*}{ Mature period } & 221.19 & 221.19 & 221.19 & 1 & 1 & 1 \\
\hline 2019.06 .01 & & 221.19 & 221.19 & 221.19 & 1 & 1 & 1 \\
\hline 2019.06 .09 & & 221.19 & 221.19 & 221.19 & 1 & 1 & 1 \\
\hline 2019.06 .18 & & 221.19 & 221.19 & 221.19 & 1 & 1 & 1 \\
\hline Whole growth period & & 2101.34 & 2488.37 & 2875.47 & 150 & 300 & 450 \\
\hline
\end{tabular}

\subsection{Measurements}

\subsubsection{Calculation of Nitrogen Content}

Biomass accumulation of tomato was determined using 9 samples per treatment in two growth stages, including fruit expanding period (55DAT-105DAT), samples destructed at 71DAT and 104DAT, and mature period (106DAT-153ADT), samples destructed at 129DAT and 150DAT, DAT refers to days after transplanting. Fresh plants were divided into several parts including root, stem, leaf and fruit, heated for $30 \mathrm{~min}$ at $105^{\circ} \mathrm{C}$ to halt metabolic processes then dried at $75^{\circ} \mathrm{C}$ until they attained a constant weight. Dry matter of different parts including; root, stem, leaf, fruit, and total dry matter were determined. The samples were then stored for further chemical analysis. Nitrogen concentration was determined using a flowing analyzer AA3. Nitrogen $(\mathrm{N})$ accumulation at 150 DAT was calculated using equation 1 and 2 [17]:

$$
\begin{gathered}
\mathrm{NA}_{\mathrm{j}}=\mathrm{DM} \times \mathrm{NC}_{\mathrm{j}} \\
\mathrm{TNA}=\sum \mathrm{NA}_{\mathrm{j}}
\end{gathered}
$$

Where NA, DM, NC, and TNA are the nitrogen accumulation in parts of plant, dry matter in parts of plant, nitrogen concentration in parts of plant and total nitrogen accumulation at 150DAT, respectively, j represent root, stem, leaf and fruit at150DAT.

\subsubsection{Calculation of Nitrogen Nutrition Index (NNI)}

Nitrogen nutrition index (NNI) can directly reflect the nutrient status of nitrogen in crops, and can be calculated as shown in equations 3 and 4 [24]:

$$
\begin{gathered}
\% \mathrm{~N}_{\mathrm{c}}=\mathrm{a}_{\mathrm{c}} \cdot \mathrm{DW} \mathrm{max}^{-b} \\
\mathrm{NNI}=\mathrm{N}_{\mathrm{t}} / \mathrm{N}_{\mathrm{c}}
\end{gathered}
$$

Where; $\% \mathrm{Nc}$ is the critical nitrogen concentration value, $a_{c}$ is the critical nitrogen concentration value when the over ground biomass is $1 \mathrm{t} / \mathrm{hm}^{2}, \mathrm{DW}_{\text {max }}$ is the maximum value of overground biomass $\left(\mathrm{t} / \mathrm{hm}^{2}\right), \mathrm{b}$ is statistical parameter which determines the slope of dilution curve in the critical nitrogen concentration, $\mathrm{Nt}$ is the measured value of nitrogen concentration $(\mathrm{g} / 100 \mathrm{~g})$, and $\mathrm{Nc}$ is the nitrogen concentration value according to dilution curve model in the critical nitrogen concentration when overground biomass is the same. When $\mathrm{NNI}=1$, the nutrient status is optimum; When $\mathrm{NNI}>1$, the nutrient status is excess; When $\mathrm{NNI}<1$, the nutrient status is deficient.

\subsubsection{Measurement of SPAD Value}

Chlorophyll content of leaves is generally measured using SPAD meter. In this study, the leaves were divided into; under leaf consisting of 11 th, 12th and13th, middle leaf consisting of 14 th, 15th and16th, and upper leaf consisting of 17th, 18th and 19 th from the bottom to the up. To prevent plant diseases, the leaves (1-9th) were disposed in blossom and fruit period (78DAT) for underside ventilation according to local management. Samples were taken every 14-19 days. The SPAD values were determined using an average of 9 samples per treatment in the growth periods, including fruit expanding period, samples destroyed at 70DAT, 89DAT and 103ADT, and mature period, as well as samples destroyed at 119DAT 133DAT and 149DAT. 9 plants were randomly selected for 
each measurement per treatment. Each leaf had three SPAD values including, one value around the midpoint of the leaf and two values around the sides of the midrib, all SPAD values were averaged [25].

\subsubsection{Measurement of Marketable Yield}

Marketable yield was determined using the average of tests done in triplicate per treatment of 9 tomato plants. Each picking yield was separated in different ranks of yield based on single fruit weight, determined via a $0.01 \mathrm{~g}$ precision electronic balance. After all the picking was done, different ranks of yield were determined. According to the investigation of purchase of tomato in the local market, they were divided into three categories based on single fruit weight: $60 \mathrm{~g} \leq \mathrm{w}<125$ $\mathrm{g}\left(\mathrm{F}_{60-125}\right), 125 \mathrm{~g} \leq \mathrm{w}<250 \mathrm{~g}\left(\mathrm{~F}_{125-250}\right)$ and $250 \mathrm{~g} \leq \mathrm{w}<350 \mathrm{~g}$ $\left(\mathrm{F}_{250-350}\right)$. Thus, the ranks of marketable yield were; small fruit yield $\left(\mathrm{F}_{60-125}\right)$, middle fruit yield $\left(\mathrm{F}_{125-250}\right)$ and big fruit yield $\left(\mathrm{F}_{250-350}\right)$, and sum of these yields is the total marketable yield. Reduction rate of different ranks in marketable yield is calculated as: $(\mathrm{Vmi}-\mathrm{Vi}) / \mathrm{Vmi} \times 100 \%$, where; $\mathrm{Vmi}$ is maximum measurement value, $\mathrm{Vi}$ is other measurement value and, $\mathrm{i}$ is different ranks in marketable yield.

\subsection{Data Analysis}

The data were analyzed by two-way analysis of covariance (ANCOVA) using DPS (Data Processing System). The significant difference of between mean values was separated multiple comparison tests at $\mathrm{p} \leq 0.05$ levels using LSD (Least-Significant Difference). Relationships between SPAD readings and other parameters were obtained by Linear or
Polynomial simulation, using Origin 2019.

\section{Results}

\subsection{Effects of Water and Nitrogen Treatments on SPAD Values and Nitrogen Accumulation}

The level of irrigation and nitrogen fertilizer application had a significant or extremely significant effect on SPAD values at different leaf positions. SPAD value at the middle of the leaf (MD-SPAD) and SPAD value of the upper leaf (UP-SPAD) was higher than SPAD value of under leaf (UD-SPAD), which gradually decreased under N1 by slightly increased first and then decreasing during growth period. MD-SPAD and UP-SPAD firstly increased and then decreased during growth period. However, UD-SPAD was significantly lower compared to other leaf positions. The SPAD values at different positions of $\mathrm{N} 2$ and $\mathrm{N} 3$ were both higher than those of N1. UP-SPAD and MD-SPAD at 103DAT recorded higher values of 66.28 and 66.25 under W2N2 treatment than under $\mathrm{W} 2 \mathrm{~N} 3$ and $\mathrm{W} 3 \mathrm{~N} 3$ treatments, respectively. There was a significant difference between W2N2 and W2N3 treatments as well as between $\mathrm{W} 2 \mathrm{~N} 3$ and $\mathrm{W} 3 \mathrm{~N} 3$ treatments. These values were much higher under W3N3 treatment than under W2N3 treatment (Figure 1). This indicates that application of nitrogen fertilizer should be appropriately increased with increasing level of irrigation to improve SPAD values. When the level of irrigation was W2, the optimum nitrogen fertilizer applied was N2.

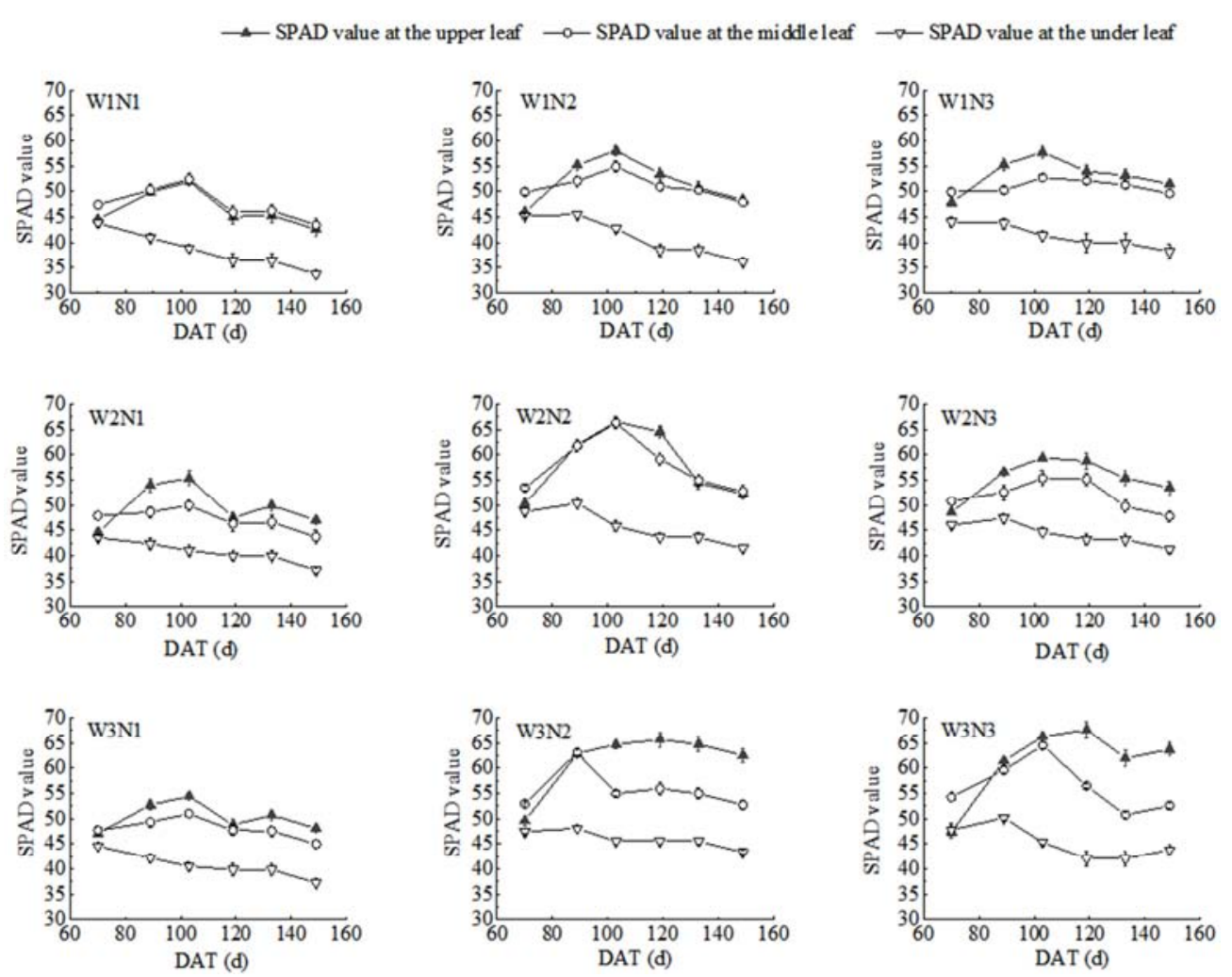

Figure 1. Trend of SPAD values at different positions under different levels of irrigation and amount of nitrogen fertilizer applied during growth period, values are mean \pm standard error. SPAD values adopted by 70DAT, 89DAT, 103DAT, 119DAT, 133DAT and 149DAT, respectively. 
According to the values of nitrogen accumulation obtained at 150DAT (Table 3), the effects of level of irrigation and amount of nitrogen fertilizer applied on leaf nitrogen accumulation (LNA), fruit nitrogen accumulation (FNA) and total nitrogen accumulation (TNA) were significant. The nitrogen accumulation of root, stem, leaf and fruit ranged from $4.07-6.55 \mathrm{~kg} \cdot \mathrm{hm}^{-2}, \quad 27.52-54.14 \mathrm{~kg} \cdot \mathrm{hm}^{-2}, \quad 41.89-60.46 \mathrm{~kg} \cdot \mathrm{hm}^{-2}$ and $80.81-157.46 \mathrm{~kg} \cdot \mathrm{hm}^{-2}$ and representing nitrogen content of TNA of about $2 \%-4 \%, 16 \%-23 \%, 20 \%-27 \%$ and $49 \%-59 \%$, respectively. This indicates that a half or more of TNA was found in the fruit, while the root had the least content. FNA and TNA were highest under W2N2 and W3N2 treatments, while N2 was the optimum nitrogen applied (Table 3).

Table 3. Effects of irrigation level and nitrogen fertilizer treatments on nitrogen accumulation.

\begin{tabular}{|c|c|c|c|c|c|}
\hline Treatments & RNA $\left(\mathrm{kg} \cdot \mathrm{hm}^{-2}\right)$ & SNA $\left(\mathrm{kg} \cdot \mathrm{hm}^{-2}\right)$ & LNA $\left(\mathrm{kg} \cdot \mathrm{hm}^{-2}\right)$ & FNA $\left(\mathrm{kg} \cdot \mathrm{hm}^{-2}\right)$ & TNA $\left(\mathrm{kg} \cdot \mathrm{hm}^{-2}\right)$ \\
\hline W1N1 & $5.43 \mathrm{ab}$ & $27.52 \mathrm{e}$ & $41.89 \mathrm{~d}$ & $80.81 \mathrm{~d}$ & $155.65 \mathrm{~d}$ \\
\hline W1N2 & $6.34 \mathrm{a}$ & $43.77 \mathrm{abc}$ & $43.39 \mathrm{~cd}$ & $98.37 \mathrm{~cd}$ & $191.88 \mathrm{bcd}$ \\
\hline W1N3 & $5.25 \mathrm{ab}$ & $40.91 \mathrm{bcd}$ & $43.75 \mathrm{~cd}$ & $86.88 \mathrm{~d}$ & $176.81 \mathrm{~cd}$ \\
\hline W2N1 & $4.07 \mathrm{~b}$ & $33.46 \mathrm{cde}$ & $42.95 d$ & $101.03 \mathrm{~cd}$ & $181.51 \mathrm{~cd}$ \\
\hline W2N2 & $6.55 \mathrm{a}$ & $45.16 \mathrm{ab}$ & $48.34 \mathrm{~cd}$ & $140.66 \mathrm{ab}$ & $240.71 \mathrm{ab}$ \\
\hline W2N3 & $5.05 \mathrm{ab}$ & $45.31 \mathrm{ab}$ & $51.70 b c$ & $125.20 \mathrm{bc}$ & $227.27 \mathrm{abc}$ \\
\hline W3N1 & $5.41 \mathrm{ab}$ & $30.30 \mathrm{de}$ & $46.46 \mathrm{~cd}$ & $104.52 \mathrm{~cd}$ & $186.69 \mathrm{~cd}$ \\
\hline W3N3 & $6.35 \mathrm{a}$ & $41.04 \mathrm{bcd}$ & $59.25 \mathrm{ab}$ & $153.10 \mathrm{ab}$ & $259.74 a$ \\
\hline W & ns & ns & $* *$ & $* *$ & $* *$ \\
\hline $\mathrm{N}$ & ns & $* *$ & $* *$ & $* *$ & $* *$ \\
\hline $\mathrm{W} * \mathrm{~N}$ & ns & $\mathrm{ns}$ & ns & ns & $\mathrm{ns}$ \\
\hline
\end{tabular}

Notes: RNA, SNA, LNA, FNA, TNA represent nitrogen accumulation of root, stem, leaf, fruit and total nitrogen accumulation, respectively; * represent F-test statistical significance at 0.05 probability level; ** represent $\mathrm{F}$-test statistical significance at the 0.01 probability level; $\mathrm{W}, \mathrm{N}$ and $\mathrm{W} * \mathrm{~N}$ represent significant level of ANOVA of water stress effect, nitrogen fertilizer and the cross effect of two factors, respectively.

\subsection{Relationships Between Nitrogen Accumulation and SPAD Values}

SPAD values and nitrogen accumulation (SNA, LNA, TNA and FNA) were positively correlated, while the determinant coefficients $\left(\mathrm{R}^{2}, \mathrm{n}=54\right)$ ranged from $0.47-0.62$ and $\mathrm{P}<0.01$ (Figure 2). This indicates that SPAD values can be used for diagnosis of nitrogen uptake.

$$
\begin{array}{ll}
\text { - Stem nitrogen accumulation } & \circ \text { Total nitrogen accumulation } \\
\text { - Leaf nitrogen accumulation } & \text { - Fruit nitrogen accumulation }
\end{array}
$$
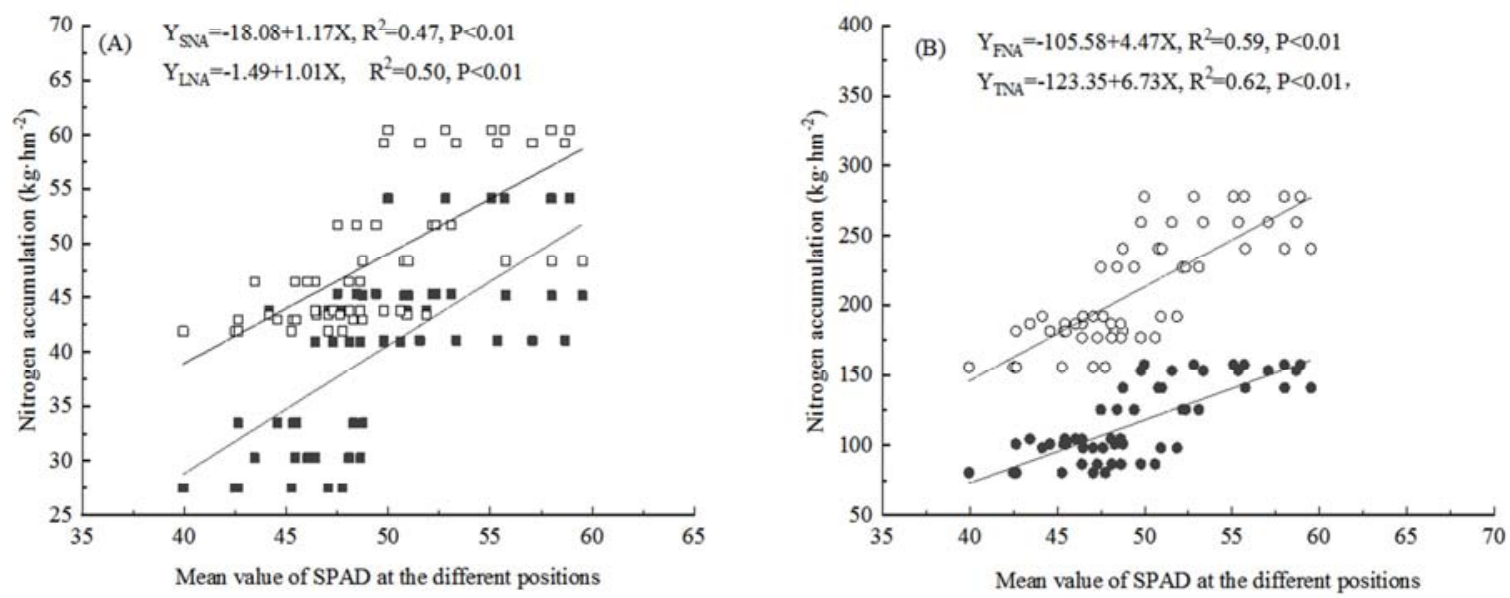

Figure 2. (A) Presents the relationships of SNA and LNA with mean value of SPAD values at different positions; (B) represent relationships of FNA and TNA with mean SPAD value at the different positions. SNA, LNA, FNA and TNA represent stem nitrogen accumulation and leaf nitrogen accumulation, fruit nitrogen accumulation and total nitrogen accumulation at 150DAT, respectively. Linear equations were shown, including determinant coefficients $\left(R^{2}\right)$ and $P$ values.

The SPAD value at different positions were positively correlated with SNA and with LNA, with $\mathrm{p}<0.05$ or $\mathrm{p}<0.01$. The determinant coefficients of the relationships of UP-SPAD with SNA and with LNA, were lower $\left(\mathrm{R}^{2}=0.22\right.$ and $\left.\mathrm{R}^{2}=0.20\right)$ than those of fruit expanding period (Figure $3 a, b$ and c). This indicates that estimation of nitrogen content (SNA and LNA) was better via MD-SPAD and UD-SPAD during fruit expanding period.

Without considering different leaf positions, the determinant coefficients were higher during mature period than during fruit expanding period except for the determinant coefficient of relationship between MD-SPAD and LNA (Figure 3d, e and f). This indicates that nitrogen accumulation (SNA and LNA) could be estimated using different leaf positions during mature 
period, specifically, UP-SPAD was the best for diagnosis of SNA and LNA during growth.

- Stem nitrogen accumulation
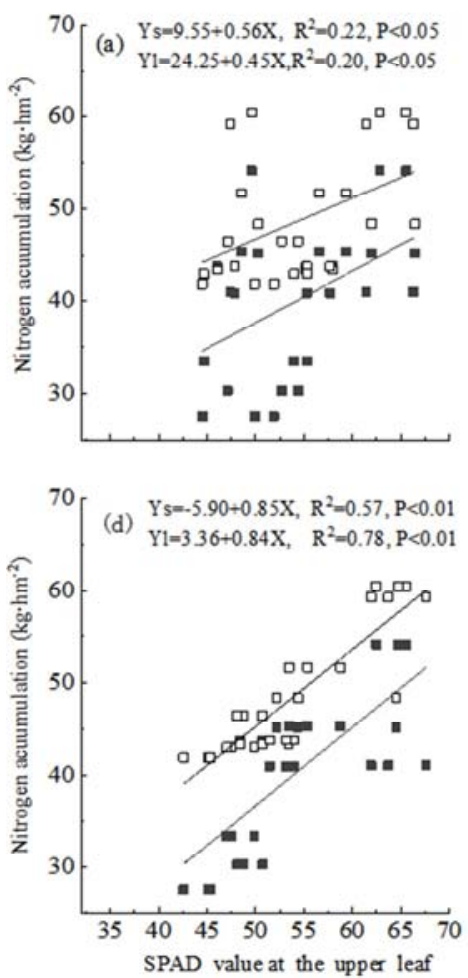
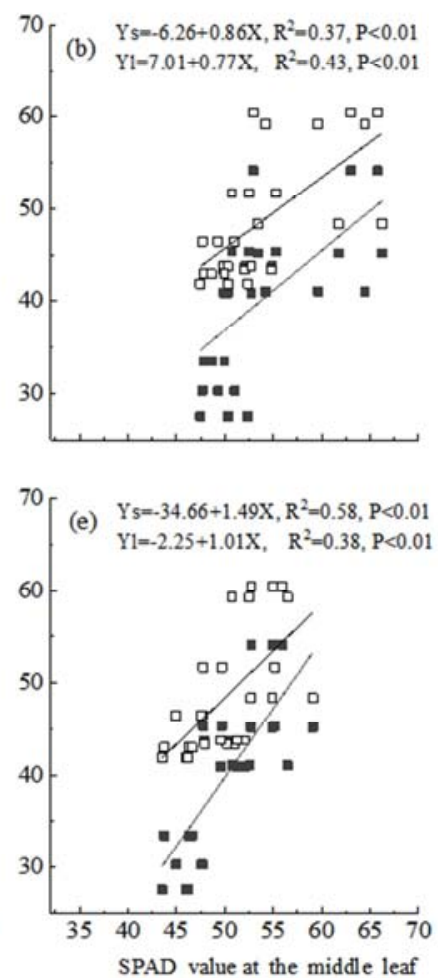
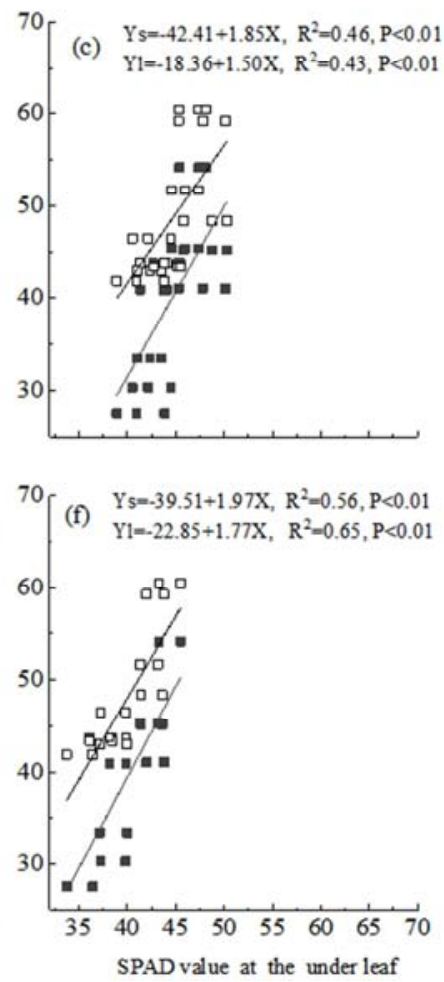

Figure 3. (a),(b) and (c) represent relationships of SNA and LNA with SPAD value at the upper leaf (UP-SPAD), with SPAD value at the middle leaf (MD-SPAD) and with SPAD value at the under leaf (UD-SPAD) during fruit expanding period, respectively. (d),(e) and (f) represent relationships of SNA and LNA with $U P-S P A D$, with MD-SPAD and with UD-SPAD during mature period, respectively. Linear equations are shown, including determinant coefficients ( $\left.R^{2}\right)$ and $P$ values.

- Total nitrogen accumulation $\quad$ Fruit nitrogen accumulation
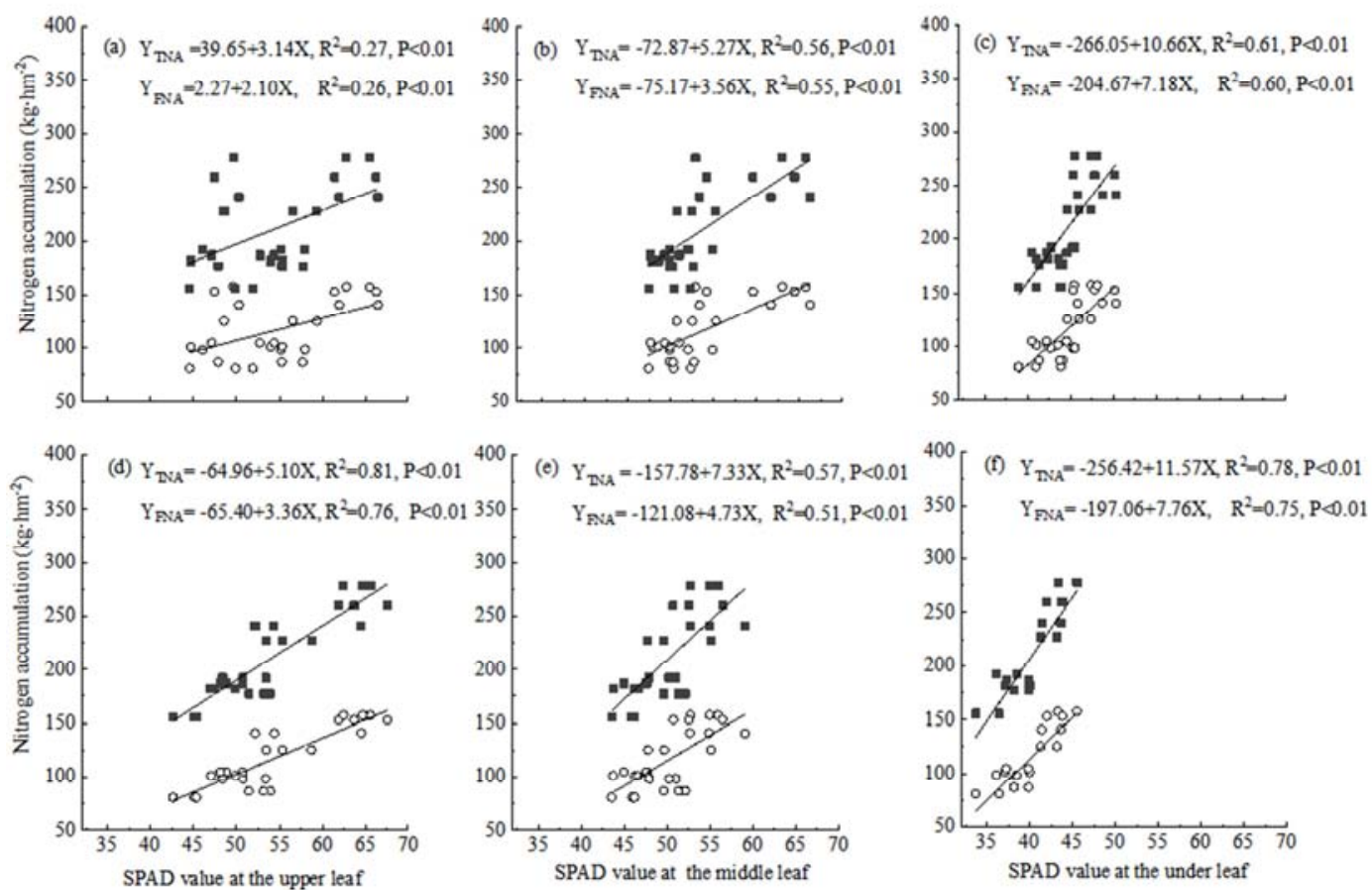

Figure 4. (a),(b), and (c) represent relationships of TNA and FNA with SPAD value at upper leaf (UP-SPAD), with SPAD value at middle leaf (MD-SPAD) and with SPAD value at under leaf (UD-SPAD) during fruit expanding period, respectively. (d),(e), and (f) represent relationships of TNA and FNA with UP-SPAD, with MD-SPAD, and with UD-SPAD during mature period, respectively. Linear equations are shown, including determinant coefficients $\left(R^{2}\right)$ and $P$ values. 
The SPAD values at different positions were positively correlated with TNA and FNA and were significantly difference $(p<0.01)$. The determinant coefficients of relationships between UP-SPAD and SNA and between UP-SPAD and LNA, were lower $\left(\mathrm{R}^{2}=0.22\right.$ and $\left.\mathrm{R}^{2}=0.20\right)$ than the others, which were $\mathrm{R}^{2}>0.50$ (Figure 4 ). This indicates that estimation of nitrogen content (TNA and FNA) was better via MD-SPAD and UD-SPAD during fruit expanding fruit period, whereas UP-SPAD was the best indicator for diagnosis of TNA and FNA during mature period.

\subsection{Relationships Between Nitrogen Nutrition Index (NNI) and SPAD Values}

During growth period, the nitrogen nutrition index (NNI) values were consistently less than those under low nitrogen treatment $(\mathrm{N} 1)$, but higher than those under middle nitrogen treatment (N2). Different levels of irrigation had significant effects on NNI values, these had marked variation under high nitrogen treatment (N3) under different levels of irrigation. NNI values of N3 were slightly higher or lower than those of growth period under full irrigation (W3). This indicates that NNI values were optimum under $\mathrm{W} 3 \mathrm{~N} 3$ treatment, whereas NNI values of N2 were gradually close to those of mature period under mild water stress (W2), NNI values was also gradually close to one in that period under N1. Different nitrogen application rates were selected based on the degree of water stress, NNI values were better under W1N1 treatment and W2N2 treatment during mature period (Figure 5).
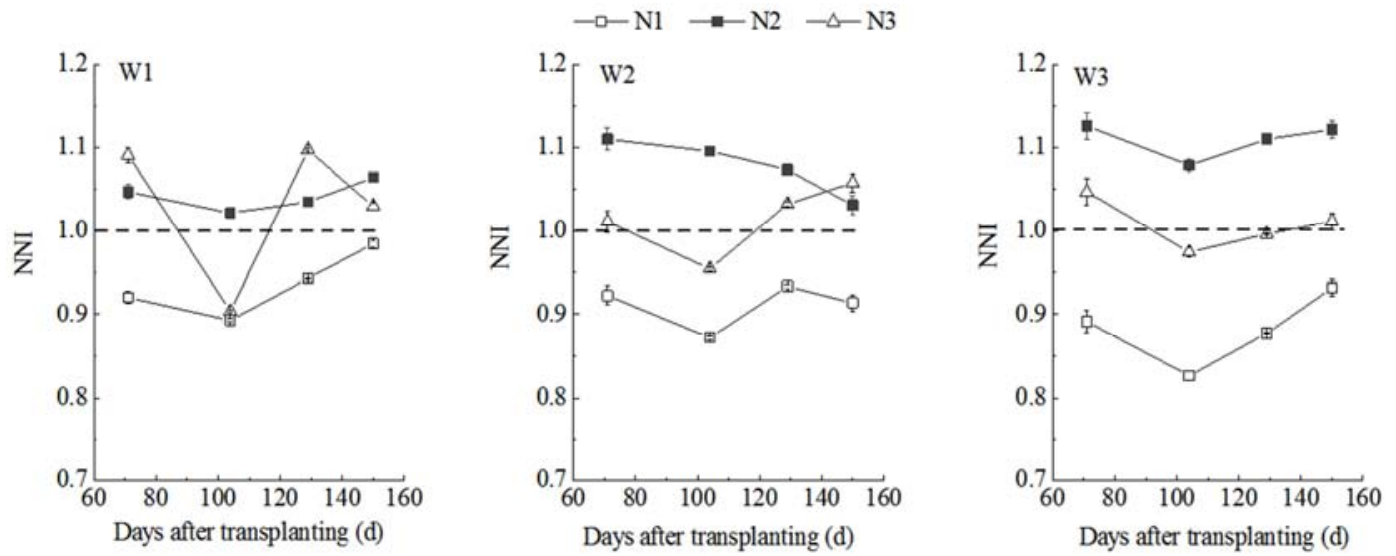

Figure 5. The dynamics of nitrogen nutrition index (NNI) values under different levels of irrigation and application of nitrogen fertilizer. Data of nitrogen concentration adopted at 71DAT, 104DAT, 129DAT, and150 DAT.

There was a highly significant difference $(\mathrm{p}<0.01)$ between NNI and SPAD values in the expanding fruit period (F-NNI) and NNI in the mature period (M-NNI) at the different positions. The determinant coefficients of the relationships of
F-NNI and M-NNI with MD-SPAD were higher than others at $\mathrm{R}^{2}<0.35$ (Figure 6). This indicates that MD-SPAD has a better accuracy in diagnosing F-NNI and M-NNI.

- NNI in developing fruit period $\circ \mathrm{NNI}$ in mature period
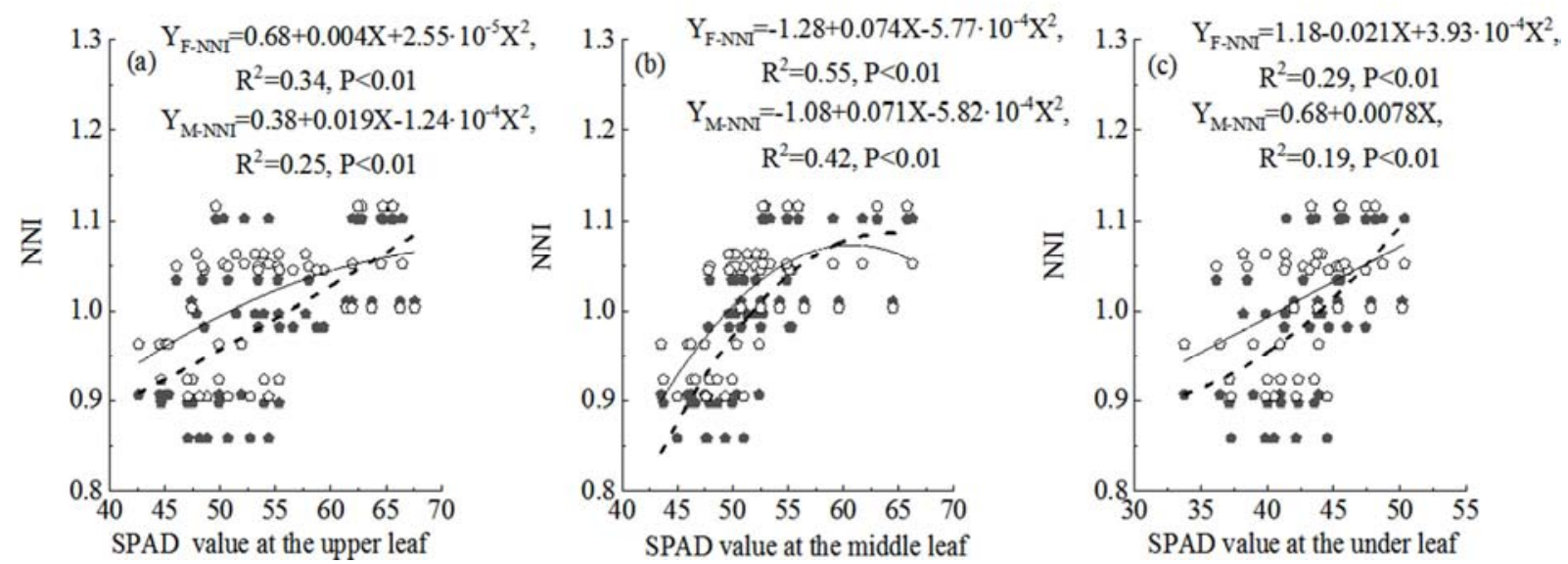

Figure 6. (a),(b), and (c) are the relationships of NNI in fruit expanding period and NNI in mature period with SPAD value at the upper leaf (UP-SPAD), with SPAD value at the middle leaf (MD-SPAD) and with PAD value under leaf (UD-SPAD), respectively. Their regression equations are shown, including determination coefficients $\left(R^{2}\right)$ and $P$ values; the dotted lines represent relationships between NNI in fruit expanding period with SPAD values at different positions; the continuous lines represent relationships between NNI in mature period with SPAD values at different positions. The NNI data in the fruit expanding period adopted mean of NNI at 71DAT and 104DAT, while the NNI data in the mature period adopted mean of NNI at 129DAT and 150 DAT. 


\subsection{Relationships Between Marketable Yield and SPAD Values}

The marketable yield was divided into three levels based on single fruit in the local market, namely small fruit yield (SFY), middle fruit yield (MFY) and big fruit yield (BFY). These occupied the total marketable yield of $11 \%-19 \%, 52 \%-55 \%$ and $32 \%-36 \%$, respectively. The total marketable yield mainly consisted of MFY and BFY, which initially increased and later decreased with irrigation levels and nitrogen fertilizer increment. There were significantly different effects between irrigation levels and nitrogen fertilizer on MFY, BFY and TMY, which were higher under W2N2 and W3N2 treatments. Moreover, there were no significant difference betweenW2N2 and W3N2 treatments for MFY, BFY and TMY (Table 4). This indicates that the irrigation levels of W2 and nitrogen fertilizer of $\mathrm{N} 2$ are important in increasing MFY, BFY and TMY.

Table 4. Effects of irrigation levels and nitrogen fertilizer treatments on the marketable yield.

\begin{tabular}{|c|c|c|c|c|}
\hline \multirow{2}{*}{ Treatments } & SFY $\left(F_{60-125}\right)$ & $\operatorname{MFY}\left(F_{125-250}\right)$ & BFY $\left(F_{250-350}\right)$ & TMY $\left(\mathrm{F}_{60-350}\right)$ \\
\hline & $\left(\mathbf{t} \cdot \mathrm{hm}^{-2}\right)$ & $\left(\mathbf{t} \cdot \mathrm{hm}^{-2}\right)$ & $\left(\mathbf{t} \cdot \mathrm{hm}^{-2}\right)$ & $\left(t \cdot h^{-2}\right)$ \\
\hline W1N1 & $11.64 \mathrm{~cd}$ & $38.57 \mathrm{e}$ & $23.99 \mathrm{c}$ & $74.19 \mathrm{e}$ \\
\hline W1N2 & $12.81 \mathrm{bc}$ & $43.89 \mathrm{de}$ & $26.27 \mathrm{c}$ & $82.98 \mathrm{de}$ \\
\hline W1N3 & $12.54 \mathrm{bcd}$ & $41.04 \mathrm{e}$ & $25.92 \mathrm{c}$ & $79.50 \mathrm{e}$ \\
\hline W2N1 & $12.32 \mathrm{~cd}$ & $51.02 \mathrm{~cd}$ & $30.75 \mathrm{c}$ & $96.10 \mathrm{bc}$ \\
\hline W2N2 & $12.66 \mathrm{bc}$ & $59.81 \mathrm{a}$ & $41.08 \mathrm{a}$ & $113.56 \mathrm{a}$ \\
\hline W2N3 & $13.58 \mathrm{~b}$ & $52.05 \mathrm{bc}$ & $34.03 \mathrm{~b}$ & $99.66 \mathrm{~b}$ \\
\hline W3N1 & $12.32 \mathrm{~cd}$ & $48.47 \mathrm{~d}$ & $29.30 \mathrm{c}$ & $90.10 \mathrm{c}$ \\
\hline W3N2 & $14.54 \mathrm{a}$ & $61.47 \mathrm{a}$ & $39.04 \mathrm{a}$ & $115.06 \mathrm{a}$ \\
\hline W3N3 & $14.45 \mathrm{ab}$ & $55.85 \mathrm{ab}$ & $36.09 \mathrm{ab}$ & $106.39 \mathrm{ab}$ \\
\hline W & $* *$ & $* *$ & $* *$ & $* *$ \\
\hline $\mathrm{N}$ & ns & $* *$ & $* *$ & $* *$ \\
\hline $\mathrm{W} * \mathrm{~N}$ & ns & ns & * & ** \\
\hline
\end{tabular}

Note: $\mathrm{F}_{60-125}, \mathrm{~F}_{125-225}, \mathrm{~F}_{250-350}$ and $\mathrm{F}_{60-350}$ represent single fruit weight $(\mathrm{FW})$ ranging from $60 \mathrm{~g} \leq \mathrm{FW}<125 \mathrm{~g}, 125 \mathrm{~g} \leq \mathrm{FW}<250 \mathrm{~g}, 250 \mathrm{~g} \leq \mathrm{FW}<350 \mathrm{~g}$ and $60 \mathrm{~g} \leq \mathrm{FW}<135 \mathrm{~g}$, respectively.

The mean SPAD value at the different positions was positively correlated with total marketable yield $\left(\mathrm{R}^{2}=0.50, \mathrm{p}<0.01, \mathrm{n}=54\right)$ (Figure 7). This indicates that SPAD value are useful in analysis of total marketable yield.

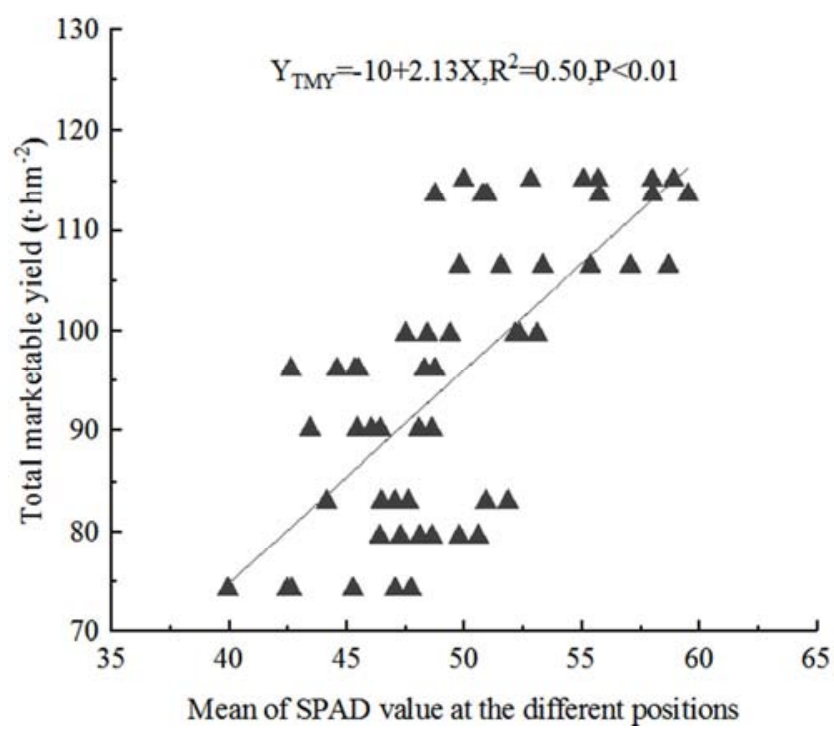

Figure 7. The relationship between mean of SPAD values and total marketable yield at the different positions. The linear equation shown encompasses determination coefficient $\left(R^{2}\right)$ and P value. Data of mean of SPAD value at the different positions adopted at $70 D A T, 89 D A T, 103$ DAT, $119 D A T, 133 D A T$ and 149 DAT.

The TMY and SPAD values at the different positions were positively correlated and significantly different $(\mathrm{p}<0.05$ or $\mathrm{P}<0.01)$. The determinant coefficient of the correlation between UP-SPAD and TMY was lower than others $\left(\mathrm{R}^{2}>0.42\right)$ This indicates that estimating TMY was better through
MD-SPAD and UD-SPAD during the fruit expanding period. Moreover, UP-SPAD and UD-SPAD were better indicators of TMY during the mature period (Figure 8). The UD-SPAD was the best indicator for diagnosing TMY during the two growth periods. 

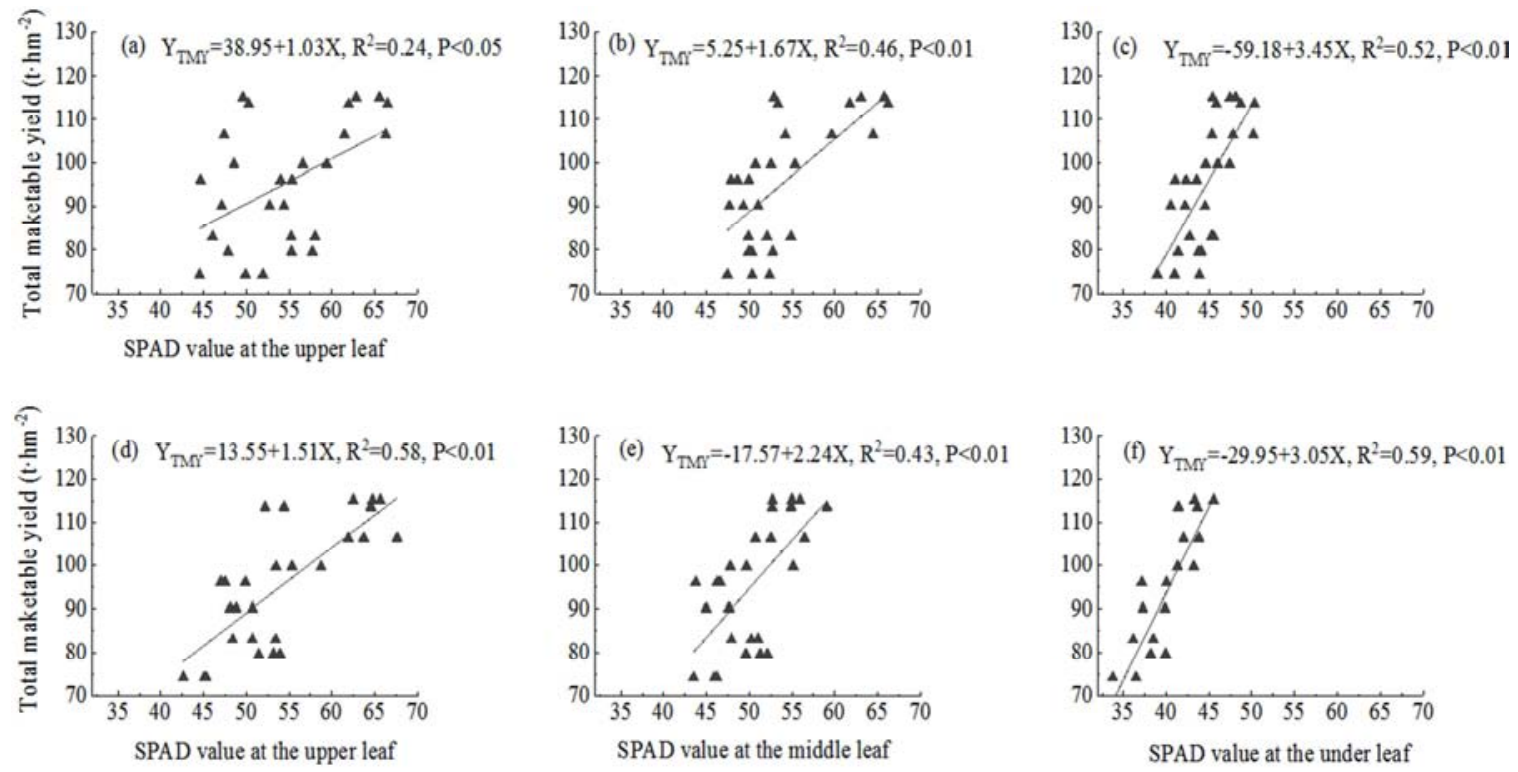

Figure 8. (a), (b) and (c) represent TNA relationships with SPAD value at the upper leaf (UP-SPAD), with SPAD value at the middle leaf (MD-SPAD) and with $P A D$ value at the under leaf (UD-SPAD) during fruit expanding period, respectively. (d), (e) and (f) represent TNA relationships with UP-SPAD, with MD-SPAD and with UD-SPAD during mature period, respectively. Respective linear equations are shown which encompasses determination coefficients $\left(R^{2}\right)$ and $P$ values.

\subsection{Quantification of Reduction Rates of the Marketable Yield}

With worsening water stress, the reduction rates of different ranks in marketable yield (SFY, MFY, BFY) and total marketable yield (TMY) increased. Maximum values were obtained under W1N1treatment and minimum values at near zero were obtained under $\mathrm{W} 2 \mathrm{~N} 2$ treatment and $\mathrm{W} 3 \mathrm{~N} 2$ treatment. In the different treatments, the reduction rate of BFY was the highest, while reduction rate of SFY was the least (Figure 9). This indicates that BFY was significantly affected by water stress.

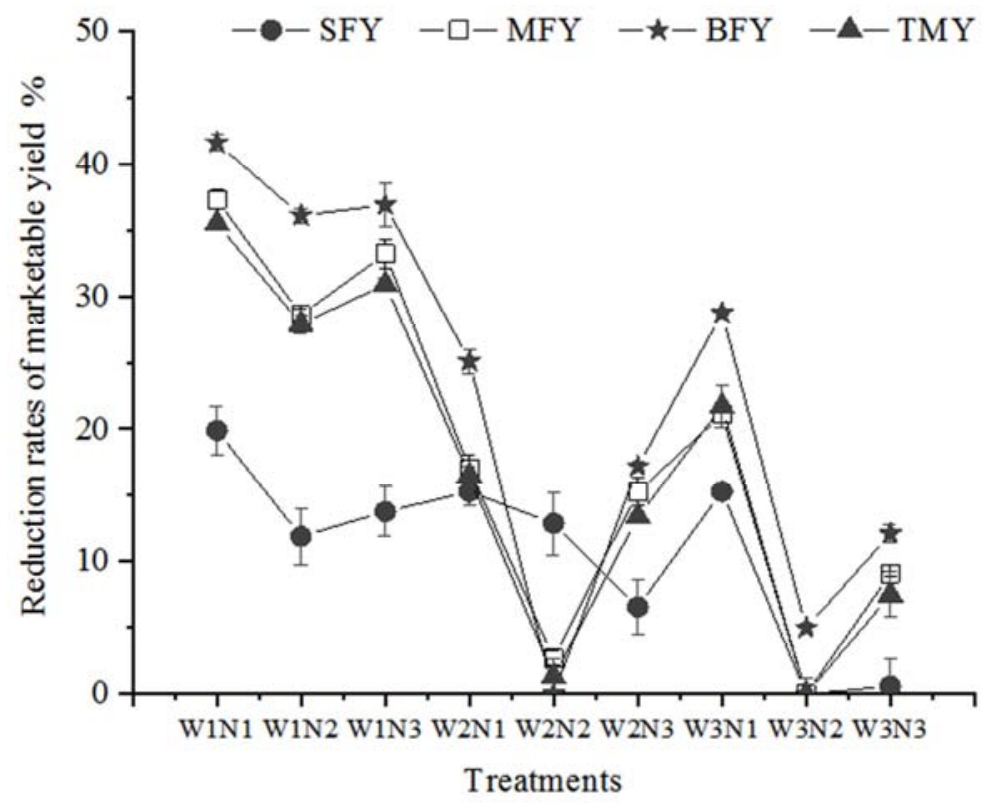

Figure 9. The reduction rates of marketable yield under the 9 different treatments. Values are mean \pm standard error.

The reduction rates of MFY, BFY, and TMY were highest under $\mathrm{W} 1$ and $\mathrm{N} 1$, ranging from $31 \%-38 \%$ and $25 \%-32 \%$, respectively. In contrast, the reduction rates of MFY, BFY and TMY were not significantly reduced under W2. When the nitrogen fertilizer application reached $\mathrm{N} 3$, the reduction rates of MFY, BFY and TMY increment was higher than N2 (Figure 10). This indicates that $\mathrm{N} 1, \mathrm{~N} 3$ and $\mathrm{W} 1$ can highly reduce yield, especially at severe water stress of $\mathrm{W} 1$ in blossom and 
fruit period.
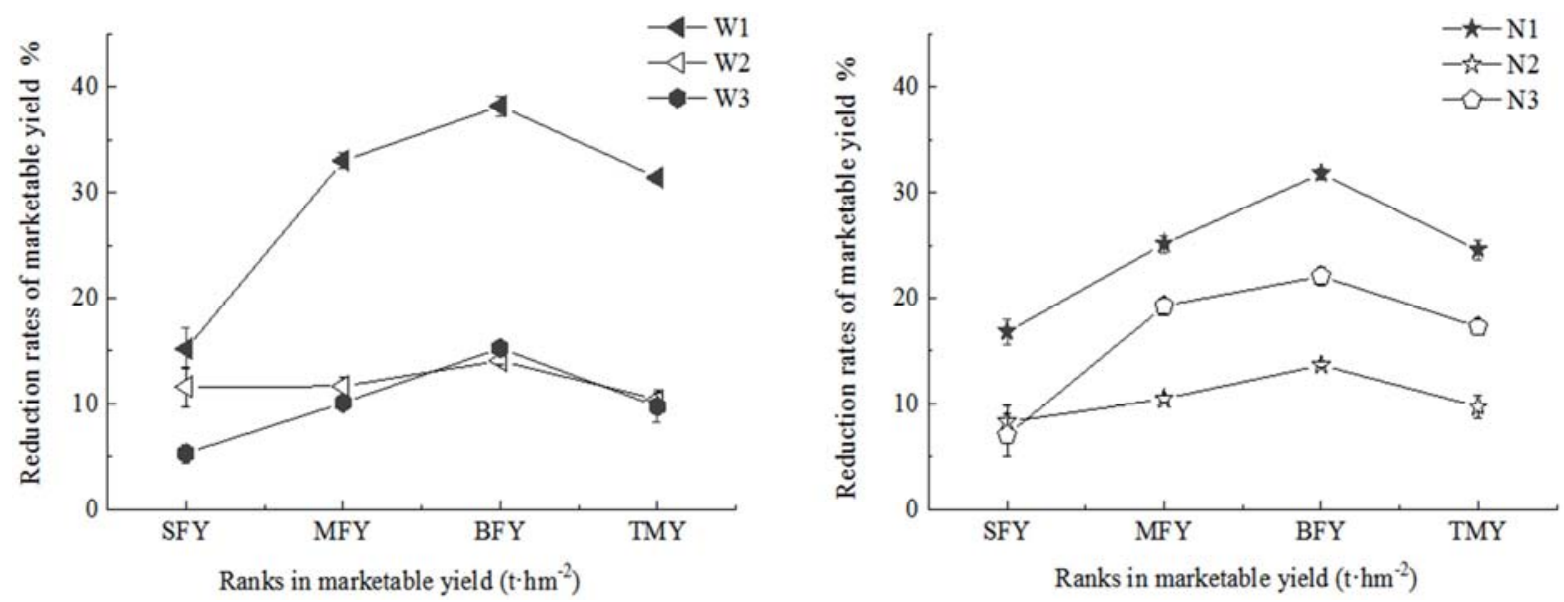

Figure 10. Quantification of reduction rates in marketable yield under three irrigation levels and three nitrogen fertilizer applications. Values are mean \pm standard error.

The reduction rates of marketable yield and mean of SPAD values at the different positions were negatively correlated and significantly different $\left(\mathrm{R}^{2}>0.47, \mathrm{P}<0.01, \mathrm{n}=54\right)$ (Figure 10.). This indicates that SPAD values can be used to predict reduction rate in marketable yield, including MFY, BFY and TMY. The linear equations differed insignificantly (intercept, slope, $\mathrm{R}^{2}$ ) and $\mathrm{p}<0.01$.

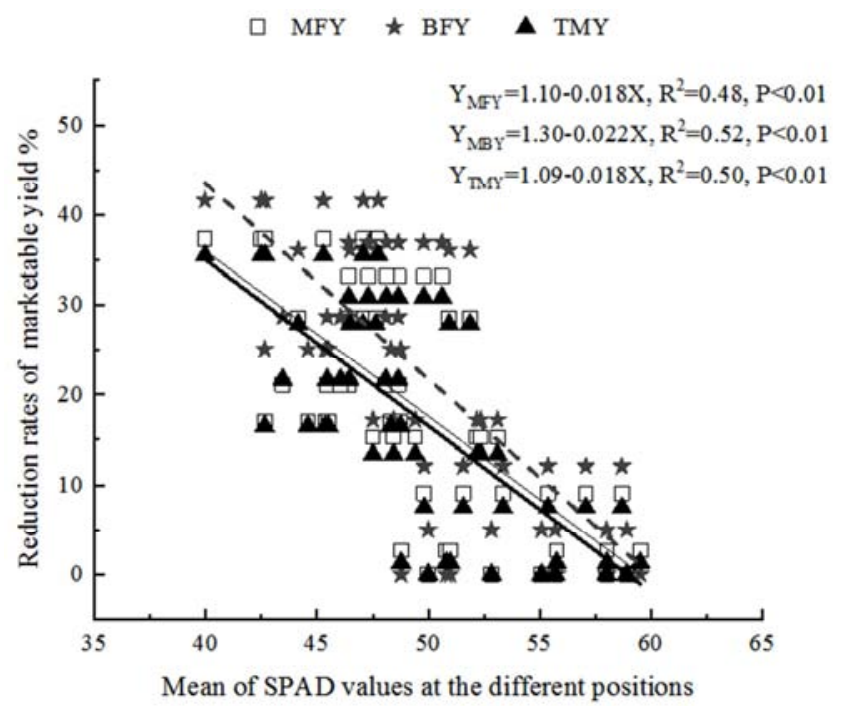

Figure 11. The relationships of reduction rates of marketable yield and mean of SPAD value at the different positions. The linear equations are indicated and includes determination coefficients $\left(R^{2}\right)$ and $P$ values.

\section{Discussion}

\subsection{Estimating the Relationships of SPAD Values and Nitrogen Status}

Nitrogen accumulation can be estimated via chlorophyll readings, by diagnosis of SPAD value at different leaf positions, but the accuracy of judgment may be different. Nitrogen status, including nitrogen accumulation of stem, leaf, fruit, total nitrogen accumulation and nitrogen nutrition index
(NNI), showed a strong relationship with SPAD value at different leaf positions. This result was consistent with previous studies which showed similar positive relationship of chlorophyll with nitrogen status in crops such as tomato [26] and cucumber [27]. The linear equations reached significant or extremely significant levels, whereas the determinant coefficients were different (Figure 3), where strong degree of relationship was different between SPAD values at different positions and nitrogen status. The weakest relationships were obtained between SPAD value at upper leaf (UP-SPAD) and nitrogen accumulation in fruit expanding period, but it was the strong relationship in mature period (Figure $3 a$ and Figure 4a). SPAD values at upper leaf may be greatly impacted by re-watering during the mature period. Previous studies have shown that re-watering in milking stage can effectively improve chlorophyll content but it still declines in mature period $[17,28]$, indicating that declining trend of chlorophyll content may be mitigated to some extent in mature period by re-watering. However, the strongest relationships between $\mathrm{NNI}$ in fruit expanding period and SPAD value were obtained in the middle leaf (MD-SPAD), as well as between NNI in mature period and MD-SPAD, and all relationships were significant (Figure 6). These results agreed with thos of previous studies that revealed that determinant coefficients were different and were most significant between SPAD indicators of different leaf positions and NNI in different growth periods [17].

The relationship between mean of SPAD values at different positions and nitrogen accumulation reached an extremely significant level in two the growth period. This indicated a good relationship between nitrogen accumulation and chlorophyll readings (Figure 2). Previous studies showed that the strongest relationship between chlorophyll readings and total-N content was realized when it was measured at the midpoint of the last fully developed leaf at the growth stage 49 [29]. However, dividing ratio of in growth period and leaf position, gives a more accurate relationship between nitrogen content and chlorophyll readings in the current study, 
especially in estimation of NNI.

\subsection{Estimation of Relationships of SPAD Values with Marketable Yield}

The total marketable yield had a positive relation with SPAD values at the different positions which reached extremely significant level (Figure 8), illustrating that the relationship of chlorophyll readings with total marketable yield was strong. The results were consistent with previous studies which revealed a positive relationship between chlorophyll readings and yield. In the current study, whereas, the relational degree was different in fruit expanding period, the strongest relationship was realized between UD-SPAD with total marketable yield (Figure 8c), followed by that between MD-SPAD and total marketable yield (Figure 8b). This indicates that the relationship was more accurate to be diagnosed by UD-SPAD and MD-SPAD, which may be greatly affected by full level of irrigation in seedling period. Earlier studies showed that the water deficit was affected significantly by total chlorophyll content which was also decreased in the vegetative stages [31], whereas chlorophyll readings at under leaf was lower than those of others, as it may not obtain full light because of being shaded by upper leaves in whole growth period. The results showed that UD-SPAD gradually declined or slightly increased first and then declined (Figure 1), due to lack of light. The study showed that the contents of chlorophyll a, chlorophyll $b$ and chlorophyll $(\mathrm{a}+\mathrm{b})$ in leaves were reducing because of shading compared to full light [32].

The determinant coefficient $\left(\mathrm{R}^{2}=0.58\right)$ of relationship of UP-SPAD with total marketable yield greatly improved in mature period (Figure 8d), due to availability of full light and re-watering, with gradual ageing of leaves, chlorophyll content was not improved by re-watering in mature period but chlorophyll readings of upper leaf was still high under W3N2 and W3N2 treatments (Figure 1). In the two growth stages, a strong relationship was obtained between mean of SPAD values at different positions and total marketable yield $\left(\mathrm{R}^{2}=50\right.$, $\mathrm{P}<0.01$ ) (Figure 7), which was similar with a previous study which showed positive relationship between chlorophyll and yield $\left(\mathrm{R}^{2}=0.67\right)[33]$.

\subsection{Effects of Water Stress and Application of Nitrogen Fertilizer on Marketable Yield}

Ranks of marketable yield, including small fruit yield (SFY), middle fruit yield (MFY), big fruit yield (BFY), and total marketable yield (TMY) were higher under irrigation levels of W2 and W3 than under severe water stress (W1), W2 was the optimal level of irrigation for saving water without reducing production. This could be because severe water stress resulted in smaller fruit size than full irrigation or mild water stress. It was found that BFY was greatly decreased by W1 compared to W2 and W3 (Figure 10), this study was consistent with earlier findings that severe water stress resulted in smaller fruit size [34]. Application of Nitrogen fertilizer $\left(300 \mathrm{~kg} \cdot \mathrm{hm}^{-2}\right)$ was beneficial in increasing of MFY,
BFY, and TMY (Table 4 and Figure 10), which were restrained by application of excessive nitrogen fertilizer, previous researches showed that excessive nitrogen may cause soil degeneration, which led to nitrogen leaching and a decline of yield [3, 35]. Strong negative relationships were revealed between reduction rates of MFY, BFY, and TMY and mean of SPAD value at different positions (Figure 11), indicating a reducting rate in yield due to water stress and application of too much or less nitrogen fertilizer could be diagnosed through SPAD values.

It was found that TMY obtained an optimal value when the level of irrigation and applied nitrogen fertilizer were W2 $(0.75 \mathrm{~W} 3)$ and $\mathrm{N} 2\left(300 \mathrm{~kg} \cdot \mathrm{hm}^{-2}\right)$, respectively (Table 4). However, previous studies showed that irrigation and fertilizer regime of $0.75 \mathrm{Ep}$ (Ep is the cumulative evaporation from a standard $20-\mathrm{cm}$ pan $(\mathrm{mm}))$ and $250 \mathrm{~kg} \mathrm{~N} \mathrm{ha}^{-1}$ were the best strategy of water and $\mathrm{N}$ management for production of drip-irrigated greenhouse tomatoes [36]. Difference could be due to different breed and irrigation plan, previous research showed that the screening of a large collection of tomato, including different fruit and cultivar types, revealed the existence of a high variability in yield [37] and different irrigation plans resulted in significantly difference in water saving and yield [38]. Re-watering in mature period, did not promote compensatory benefit of production, indicating that severe water stress in the critical period had impacted production hugely. Studies have shown that the severe water deficit (one-third of full irrigation) at the flowering and fruit development stage, result in decreased yield [39, 40].

\section{Conclusions}

Without considering growth period and the leaf positions individually, this study showed that SPAD values can be used to estimate nitrogen status, total marketable yield and reduction rates of marketable yield. When considering the growth period and leaf positions individually, SPAD value at middle leaf and under leaf may be more suitable for estimating nitrogen accumulation and total marketable yield in growth period, whereas SPAD value at upper leaf may be the most accurate diagnosis for nitrogen accumulation and total marketable yield in fruit expanding period which is opposite in mature period. Without considering growth period individually, SPAD value at the middle leaf could be a more accurate indicator of nitrogen nutrition index (NNI). When simultaneously considering estimation of nitrogen accumulation, NNI and marketable yield using chlorophyll readings, mean of SPAD values adopted by different leaf positions or SPAD value at the middle leaf could be used to more accurate estimate nitrogen content and yield.

SPAD values and nitrogen accumulation, including those of stem, leaf, fruit and total nitrogen accumulation, were higher under $\mathrm{W} 2 \mathrm{~N} 2, \mathrm{~W} 2 \mathrm{~N} 3, \mathrm{~W} 3 \mathrm{~N} 2$ and $\mathrm{W} 3 \mathrm{~N} 3$ treatments. Total marketable yield was optimal under W2 of $2488 \mathrm{~m}^{3} \cdot \mathrm{hm}^{-2}$ and $\mathrm{N} 2$ of $300 \mathrm{~kg} \cdot \mathrm{hm}^{-2}$ and reduction rate of big fruit yield was the highest than that of others, thus big fruit yield could be greatly affected by severe water stress in blossom and fruit periods. 


\section{Acknowledgements}

Funding for this study was provided in part by the 863 Program of National High-Tech R\&D Program of China (2013AA103004) and the Water and Technology Support Plan of Shaanxi Province, China (2014slkj-17). The authors also express our sincere gratitude to reviewers.

\section{References}

[1] Jiang Hui-Min, Z. J. S. X. and Jun-Cheng, A. Y. 2012. Responses of Agronomic Benefit and Soil Quality to Better Management of Nitrogen Fertilizer Application in Greenhouse Vegetable Land. Soil Science Society of China. 5, 650-660.

[2] $\mathrm{Xu}$, J. et al. 2020. Exploring optimal irrigation and nitrogen fertilization in a winter wheat-summer maize rotation system for improving crop yield and reducing water and nitrogen leaching. Agricultural Water Management. 228, 105904.

[3] Li, Y.; Sun, Y.; Liao, S.; Zou, G.; Zhao, T.; Chen, Y.; Yang, J.; Zhang, L. 2017. Effects of two slow-release nitrogen fertilizers and irrigation on yield, quality, and water-fertilizer productivity of greenhouse tomato. Agricultural Water Management. 186, 139-146.

[4] Badr, M. A.; Abou-Hussein, S. D.; El-Tohamy, W. A. 2016. Tomato yield, nitrogen uptake and water use efficiency as affected by planting geometry and level of nitrogen in an arid region. Agricultural Water Management. 169, 90-97.

[5] Li, J.; Wang, Y.; Zhang, M.; Liu, Y.; Xu, X.; Lin, G.; Wang, Z.; Yang, Y.; Zhang, Y. 2019. Optimized micro-sprinkling irrigation scheduling improves grain yield by increasing the uptake and utilization of water and nitrogen during grain filling in winter wheat. Agricultural Water Management. 211, 59-69.

[6] Zhang, M.; Dong, B.; Qiao, Y.; Shi, C.; Yang, H.; Wang, Y.; LIU, M. 2018. Yield and water use responses of winter wheat to irrigation and nitrogen application in the North China Plain. Journal of Integrative Agriculture. 17, 1194-1206.

[7] Zhang, H.; Chi, D.; Wang, Q.; Fang, J.; Fang, X. 2011. Yield and Quality Response of Cucumber to Irrigation and Nitrogen Fertilization Under Subsurface Drip Irrigation in Solar Greenhouse. Agricultural Sciences in China. 10, 921-930.

[8] Sun, Y.; Zhang, J.; Wang, H.; Wang, L.; Li, H. 2019. Identifying optimal water and nitrogen inputs for high efficiency and low environment impacts of a greenhouse summer cucumber with a model method. Agricultural Water Manage. 212, 23-34.

[9] Peng, S.; Garcia, F. V.; Laza, R. C.; Sanico, A. L.; Visperas, R. M.; Cassman, K. G. 1996. Increased N-use efficiency using a chlorophyll meter on high-yielding irrigated rice. Field Crops Research. 47, 243-252.

[10] Zheng, H.; Liu, Y.; Qin, Y.; Chen, Y.; Fan, M. 2015. Establishing dynamic thresholds for potato nitrogen status diagnosis with the SPAD chlorophyll meter. Journal of Integrative Agriculture. 14, 190-195.

[11] Huang, L.; Yu, J.; Yang, J.; Zhang, R.; Bai, Y.; Sun, C.; Zhuang, H. 2016. Relationships Between Yield, Quality and Nitrogen Uptake and Utilization of Organically Grown Rice Varieties. Pedosphere. 26, 85-97.
[12] Gholizadeh, A.; Saberioon, M.; Borůvka, L.; Wayayok, A.; Mohd Soom, M. A. 2017. Leaf chlorophyll and nitrogen dynamics and their relationship to lowland rice yield for site-specific paddy management. Information Processing in Agriculture. 4, 259-268.

[13] Zhao, B.; Liu, Z.; Ata-Ul-Karim, S. T.; Xiao, J.; Liu, Z.; Qi, A.; Ning, D.; Nan, J.; Duan, A. 2016. Rapid and nondestructive estimation of the nitrogen nutrition index in winter barley using chlorophyll measurements. Field Crops Research. 185, 59-68.

[14] Liu, S.; Li, L.; Gao, W.; Zhang, Y.; Liu, Y.; Wang, S.; Lu, J. 2018. Diagnosis of nitrogen status in winter oilseed rape (Brassica napus L.) using in-situ hyperspectral data and unmanned aerial vehicle (UAV) multispectral images. Computers and Electronics in Agriculture. 151, 185-195.

[15] Ravier, C.; Quemada, M.; Jeuffroy, M. 2017. Use of a chlorophyll meter to assess nitrogen nutrition index during the growth cycle in winter wheat. Field Crops Research. 214, 73-82.

[16] Xiong, D.; Chen, J.; Yu, T.; Gao, W.; Ling, X.; Li, Y.; Peng, S.; Huang, J. 2015. SPAD-based leaf nitrogen estimation is impacted by environmental factors and crop leaf characteristics. Scientific Reports. 5, 13389.

[17] Yuan, Z.; Ata-Ul-Karim, S. T.; Cao, Q.; Lu, Z.; Cao, W.; Zhu, Y.; Liu, X. 2016. Indicators for diagnosing nitrogen status of rice based on chlorophyll meter readings. Field Crops Research. 185, 12-20.

[18] Bauerle, W. L.; Weston, D. J.; Bowden, J. D.; Dudley, J. B.; Toler, J. E. 2004. Leaf absorptance of photosynthetically active radiation in relation to chlorophyll meter estimates among woody plant species. Scientia Horticulturae. 101, 169-178.

[19] Hawkins, T. S.; Gardiner, E. S.; Comer, G. S. 2009. Modeling the relationship between extractable chlorophyll and SPAD-502 readings for endangered plant species research. Journal for Nature Conservation. 17, 123-127.

[20] Puangbut, D.; Jogloy, S.; Vorasoot, N. 2017. Association of photosynthetic traits with water use efficiency and SPAD chlorophyll meter reading of Jerusalem artichoke under drought conditions. Agricultural Water Manage. 188, 29-35.

[21] Amirruddin, A. D.; Muharam, F. M.; Ismail, M. H.; Ismail, M. F.; Tan, N. P.; Karam, D. S. 2020. Hyperspectral remote sensing for assessment of chlorophyll sufficiency levels in mature oil palm (Elaeis guineensis) based on frond numbers: Analysis of decision tree and random forest. Computers and Electronics in Agriculture. 169, 105221.

[22] Ahmad, I.; Dole, J. M.; Nelson, P. 2012. Nitrogen application rate, leaf position and age affect leaf nutrient status of five specialty cut flowers. Scientia Horticulturae. 142, 14-22.

[23] Padilla, F. M.; Peña-Fleitas, M. T.; Gallardo, M.; Giménez, C.; Thompson, R. B. 2017. Derivation of sufficiency values of a chlorophyll meter to estimate cucumber nitrogen status and yield. Computers and Electronics in Agriculture. 141, 54-64.

[24] Lemaire, G.; Denoix, A. 1987. Croissance estivale en matière sèche de peuplements de fétuque élevée (Festuca arundinacea Schreb.) et de dactyle (Dactylis glomerata L.) dans l'Ouest de la France. II. Interaction entre les niveaux d'alimentation hydrique et de nutrition azotée. Agronomie. 7, 381-389.

[25] Shaobing Peng, F. V. G. R. 1993. Adjustment for Specific Leaf Weight Improves Chlorophyll Meter'sEstimate of Rice Leaf Nitrogen Concentration. Agron Journal. 85, 987-990. 
[26] F. M. Padilla, M. T. P. M. 2015. Threshold values of canopy reflectance indices and chlorophyll meter readings for optimal nitrogen nutrition of tomato. Annals of Applied Biology ISSN. $166,271-285$

[27] Padilla, F. M.; Peña-Fleitas, M. T.; Gallardo, M.; Thompson, R. B. 2016. Proximal optical sensing of cucumber crop N status using chlorophyll fluorescence indices. European Journal of Agronomy. 73, 83-97.

[28] Li, Y.; Song, H.; Zhou, L.; Xu, Z.; Zhou, G. 2019. Tracking chlorophyll fluorescence as an indicator of drought and rewatering across the entire leaf lifespan in a maize field. Agricultural Water Manage. 211, 190-201.

[29] Hoel, B. O. 1998. Use of a hand-held chlorophyll meter in winter wheat: Evaluation of different measuring positions on the leaves. Acta Agriculturae Scandinavica, Section B - Soil \& Plant Science. 48, 222-228.

[30] Bavec, F.; Bavec, M. 2001. Chlorophyll meter readings of winter wheat cultivars and grain yield prediction. Communications in Soil Science and Plant Analysis. 32, 2709-2719.

[31] De, C.; Neto, O.; Lobato, A.; Gonçalves-Vidigal, C.; Cezar, R.; Costa, L.; Gomes, B.; Filho, B.; Alves, G.; Mello, W., et al. 2009. Carbon compounds and chlorophyll contents in sorghum submitted to water deficit during three growth stages. Journal of Food Agriculture and Environment. 7, 588-593.32.

[32] Sarijeva, G.; Knapp, M.; Lichtenthaler, H. K. 2007. Differences in photosynthetic activity, chlorophyll and carotenoid levels, and in chlorophyll fluorescence parameters in green sun and shade leaves of Ginkgo and Fagus. Journal of Plant Physiology. 164.950-955.

[33] Talwar, H. S.; Surwenshi, A.; Seetharama, N. 2009. Use of SPAD chlorophyll meter to screen sorghum (Sorghum bicolor) lines for postflowering drought tolerance. Indian Journal of Agricultural Sciences. 79, 35-39.

[34] Topcu, S.; Kirda, C.; Dasgan, Y.; Kaman, H.; Cetin, M.; Yazici, A.; Bacon, M. A. 2007. Yield response and N-fertiliser recovery of tomato grown under deficit irrigation. European Journal of Agronomy. 26, 64-70.

[35] Wu, H.; Du, S.; Zhang, Y.; An, J.; Zou, H.; Zhang, Y.; Yu, N. 2019. Effects of irrigation and nitrogen fertilization on greenhouse soil organic nitrogen fractions and soil-soluble nitrogen pools. Agricultural Water Manage. 216, 415-424.

[36] Du, Y.; Cao, H.; Liu, S.; Gu, X.; Cao, Y. Response of yield, quality, water and nitrogen use efficiency of tomato to different levels of water and nitrogen under drip irrigation in Northwestern China. J Integr Agr 2017, 16, 1153-1161.

[37] Fullana-Pericàs, M.; Conesa, M. À.; Douthe, C.; El Aou-ouad, H.; Ribas-Carbó, M.; Galmés, J. 2019. Tomato landraces as a source to minimize yield losses and improve fruit quality under water deficit conditions. Agricultural Water Manage. 223, 105722 .

[38] Wang, F.; Kang, S.; Du, T.; Li, F.; Qiu, R. 2011. Determination of comprehensive quality index for tomato and its response to different irrigation treatments. Agricultural Water Management. 98, 1228-1238.

[39] Chen, J.; Kang, S.; Du, T.; Qiu, R.; Guo, P.; Chen, R. 2013. Quantitative response of greenhouse tomato yield and quality to water deficit at different growth stages. Agricultural Water Management. 129, 152-162.

[40] Jiang, X.; Zhao, Y.; Tong, L.; Wang, R.; Zhao, S. 2019. Quantitative Analysis of Tomato Yield and Comprehensive Fruit Quality in Response to Deficit Irrigation at Different Growth Stages. Hortscience. 54, 1409-1417. 